\title{
Effect of activated clinoptilolite and inactive brewer's yeast mixture on loin eye muscle and body indexes in fattening period"1)
}

\author{
SELIM ESEN, HARUN KARADAG*, CUNEYT KAPTAN**, HUSEYIN ESECELI***
}

\begin{abstract}
Department of Feed and Animal Nutrition, Sheep Breeding Research Institute, Balikesir, Turkey *Bursa Directorate of Provincial Agriculture and Forestry, Republic of Turkey Ministry of Agriculture and Forestry, Bursa, Turkey **Branch of Animal Health, Department of Production and Operation, Sheep Breeding Research Institute, Balikesir, Turkey ***Department of Animal Nutrition and Nutritional Diseases, Faculty of Veterinary, Kastamonu University, Kastamonu, Turkey
\end{abstract}

Esen S., Karadag H., Kaptan C., Eseceli H.

Effect of activated clinoptilolite and inactive brewer's yeast mixture on loin eye muscle and body indexes in fattening period

\section{Summary}

This study was conducted to determine the effects of dietary activated clinoptilolite and inactive brewer's yeast mixture (CBY) on the loin eye muscle (MLD) and body indexes. For this purpose, a total of 48 Kivircik male lambs at the weaning age of $62 \pm 4$ days and with the initial live weight of $23.80 \pm 3.19 \mathrm{~kg}$ were randomly allocated to one control group (CON) and three treatments groups (namely CBY-I, CBY-II, and CBY-III), each containing 12 lambs. $0,1,3$, and $5 \mathrm{~g} / \mathrm{kg}$ of CBY were added to the diets, respectively, as fed basis. The trial lasted for 63 days, of which 7 days were spent for adaptation to the diets and $\mathbf{5 6}$ days for the data collection. All the animals received $150 \mathrm{~g}$ of chopped alfalfa hay and their specifically formulated experimental diets $\mathrm{ad}$ libitum. There was no significant difference between the treatments in terms of MLD depth and fat thickness (FT) $(p>0.05)$. The addition of 3 and $5 \mathrm{~g} / \mathrm{kg}$ CBY to the lamb diets increased the MLD depth $(+1.87 \%$ in CBY-II and $+4.67 \%$ in CBY-III) and decreased the FT (-13.29\% in CBY-II). Furthermore, a significant difference was observed between the treatments in terms of index of height $(\mathrm{IH})(\mathrm{p}<0.05)$. It was concluded that adding $3 \mathrm{~g} / \mathrm{kg}$ CBY to the lamb diets to increase the MLD depth, decrease the FT, and improve the body indexes may have some economic benefits in the fattening period.

Keywords: clinoptilolite, brewer's yeast, loin eye muscle, body indexes, fattening

One of the main goals of the lamb meat production industry is to improve the meat quality with a higher growth rate and with lower feed consumption. Therefore, both meat and livestock industries have been constantly seeking new ways to achieve this main goal. However, consumers' preferences play an important role in specifying the quantity and quality standards of lamb meat in the market and often act as a limiting factor for these industries (20).

In last decades, the use of both natural and synthetic silicate minerals and by-products of the fermentation industry in animal nutrition has increased mainly due to their positive effects on animal performance and health. Clinoptilolite, natural hydrated aluminosilicates, and

The present study was supported by the Republic of Turkey, Ministry of Agriculture and Forestry, General Directorate of Agricultural Research (Project No: TAGEM/HSGYAD/B/19/A4/B2/1026). The authors would like to thank Orgamin Ltd. Co. and Atayem Ltd. Co. for their contribution. brewer's yeast, a by-product of breweries, are two of these materials that have been increasingly used in animal nutrition. Moreover, some processes such as the activation of clinoptilolite and inactivation of brewer's yeast are necessary to increase the adsorption capacity of clinoptilolite and eliminate further fermentation of brewer's yeast after consumption $(2,5)$. While activated and micronized clinoptilolites, known as good adsorbent and toxin binders, are primarily used for detoxfiying the heavy metals, $\mathrm{O}_{2}$, reactive oxygen species (ROS) and aflatoxins; the inactivated brewer's yeast is mostly used to increase the dry matter intake and nutrient digestibility, regulate the rumen $\mathrm{pH}$, and reduce amonia in ruminants $(3,9,12,16)$.

Previous studies on meat production industry have primarily focused on improving the average daily gain (ADG) and the feed conversion ratio in ruminants $(6$, $7,14)$. The extent of the performance enhancement 
directly depends on the type of the materials used, their purity and physicochemical properties, and the supplementation level used in the diets. However, there is a lack of information about the effect of these two materials on body indexes when used as a growth promotor. Therefore, the purpose of this study was to examine the effects of activated clinoptilolite and brewer's yeast mixture (CYB) with different dietary levels, as a growth promotor, on the body indexes of fattening lambs. Furthermore, the musculus longissimus dorsi (MLD) and fat thickness (FT) of lambs were also examined.

\section{Material and methods}

All animal care and handling procedures were reviewed and approved by the Ethical Committee of the Sheep Breeding Research Institute (Approval number: 3760010). All efforts were made to minimize any discomfort during the body measurements.

Animals, diets, and experimental design. This research trial was conducted at the experimental unit of the Sheep Breeding Research Institute, Balıkesir, Turkey, from April to June 2019. A total of forty eight Kivircik male lambs at the weaning age of $62 \pm 4$ days and with the initial live weight $(\mathrm{LW})$ of $23.80 \pm 3.19 \mathrm{~kg}$ (mean $\pm \mathrm{SD})$ were used in this study. In all, the experiment lasted for 63 days, of which

Tab. 1. Ingredients and chemical compositions of diets

\begin{tabular}{|l|r|r|r|r|}
\hline \multicolumn{1}{|c|}{ Raw material (g/kg fed basis) } & \multicolumn{4}{c|}{ Treatments } \\
\hline Bonkalite flour & CON & CBY-I & CBY-II & CBY-III \\
\hline Sunflower meal & 245 & 244 & 242 & 240 \\
\hline Maize grain & 155 & 155 & 155 & 155 \\
Corn extract meal & 150 & 150 & 150 & 150 \\
\hline Wheat, cracked & 130 & 130 & 130 & 130 \\
\hline DDGS ${ }^{1}$ & 100 & 100 & 100 & 100 \\
\hline Rice bran & 50 & 50 & 50 & 50 \\
\hline Rice & 50 & 50 & 50 & 50 \\
\hline Molasses & 40 & 40 & 40 & 40 \\
\hline Limestone & 40 & 40 & 40 & 40 \\
\hline Salt & 30 & 30 & 30 & 30 \\
\hline Ammonium chloride & 5 & 5 & 5 & 5 \\
\hline Vitamin-mineral premix ${ }^{2}$ & 4 & 4 & 4 & 4 \\
\hline CYB ${ }^{3}$ & 1 & 1 & 1 & 1 \\
\hline Chemical composition (g/kg DM basis) & & & 3 & 5 \\
\hline DM (g/kg fresh basis) & 890.7 & 883.6 & 890.7 & 883.1 \\
\hline CP & 168.2 & 166.5 & 168.1 & 166.2 \\
\hline CA & 81.3 & 76.7 & 78.3 & 80.6 \\
\hline EE & 35.8 & 36.1 & 35.6 & 35.5 \\
\hline CF & 106.0 & 105.7 & 104.8 & 103.8 \\
\hline
\end{tabular}

Explanations: ${ }^{1}$ distiller's dried grains with solubles; ${ }^{2}$ premix $(/ \mathrm{kg})$ : vitamin A$5000 \mathrm{IU}$, vitamin D - $1000 \mathrm{IU}$, vitamin E - $20 \mathrm{IU}, \mathrm{Zn}-150 \mathrm{mg}, \mathrm{Mn}-80 \mathrm{mg}$, $\mathrm{Mg}-200 \mathrm{mg}, \mathrm{Co}-5 \mathrm{mg}, \mathrm{I}-1 \mathrm{mg}$; ${ }^{3}$ activated clinoptilolite and brewer's yeast mixture (w/w; 60/40\%)
7 days were spent for adaptation to the diets and 56 days for the data collection. The lambs were randomly divided into 4 experimental groups and adapted to the concentrate for 1 week before the study to reduce the incidence of rumen acidosis. During the adaptation period, all animals were treated with ivermectin against internal and external parasites. They were kept in individual pens $(1.2 \mathrm{~m} \times 1.5 \mathrm{~m})$ equipped with zeolite-bedded concrete-floor and provided free access to water and mineral licking blocks.

The lambs were randomly allocated to one of the four groups $(\mathrm{n}=12$ per dietary treatment). One of these treatment groups received the control diet $(\mathrm{CON})$ while the other three groups (namely CBY-I, CBY-II, and CBY-III) received different doses of activated clinoptilolite and inactive brewer's yeast mixture (CBY; w/w, 60/40\%) in their diets $(1,3$, and $5 \mathrm{~g} / \mathrm{kg}$, respectively, as fed basis). In this study, the activated clinoptilolite and inactive brewer's yeast were provided from Orgamin Ltd. Co. (Bandırma, Balıkesir, Turkey) and the formulated diets were pelleted at Atayem Ltd. Co. (Gönen, Balıkesir, Turkey). All the animals received $150 \mathrm{~g}$ of chopped alfalfa hay and their specifically formulated experimental diets ad libitum, twice a day at 09:00 and 16:30 h. The chemical composition of the diets used in this study is given in the Table 1 .

Chemical analysis of feedstuffs. The dry matter (DM), crude protein $(\mathrm{CP})$, crude ash (CA), ether extract (EE), and crude fibre $(\mathrm{CF})$ compositions of the trial diets were analyzed according to AOAC methods (1).

Live weight and morphometric measurements. The LW and morphometric measurements of lambs were recorded on the same day after adaptation and at the end of the trial. The LWs of the lambs were individually measured using an ovine weight scale after at least $12 \mathrm{~h}$ of fastening period. The morphometric measurements were taken from the animals in a standing position with a raised head by the same technician in order to avoid inter-individual variations.

In this study, the following morphometric traits were measured according to Y1lmaz et al. (21): Body length (BL), withers height (WH), rump height (RH), rump width (RW), chest depth (CD), chest width $(\mathrm{CW})$, chest circumference (CC), and cannon-bone circumference (CBC). A flexible calibrated tape was used to measure the circumference whereas the callipers were used for measuring the depth, length and width.

Body measurement indexes. Both the ethnological and functional indexes which contribute to the breed characteristics, type, purpose, and performance were calculated as follows $(4,11$, 13, 17, 19).

Ethnological indexes: index of body frame $(\mathrm{IBF})=B L / W H \times 100$; index of chest $(\mathrm{IC})=C W /$ $C D \times 100$; index of height $(\mathrm{IH})=W H / R H \times 100$.

Functional indexes: index of chest depth $(\mathrm{ICD})=C D / W H \times 100$; index of thorax development (ITD) $=C C / W H \times 100$; dactyl thorax index $(\mathrm{DTI})=C B C / C C \times 100$; index of anamorphosis $(\mathrm{IA})=(C C)^{2} / \mathrm{WH}$; index of relative cannon bone 
$($ IRCB $)=C B C / W H \times 100$; index of body weight $($ IBW $)=$ $B W / W H \times 100$.

Ultrasound measurements. The loin eye muscle (MLD) and the FT between the $12^{\text {th }}$ and $13^{\text {th }}$ ribs of each lamb were monitored using Mindray DP-20 ultrasound device and the 75L50EAV model of transrectal linear probe $(7.5 \mathrm{MHz})$ after the morphometric measurements at each period.

Statistical analysis. The effect of independent factors (treatments and period) on the indexes in question was analyzed using the GLM procedure of Minitab (15) statistical package program, and the least squares means were compared using the Tukey's multiple comparison tests. The model used for the least squares (LS) analysis was as follows:

$$
Y_{i j k}=\mu+T_{i}+P_{j}+(T \times P)_{i j}+e_{i j k}
$$

where: $Y_{i j k}$ represents the value measured at the period $\mathrm{j}$ for the treatment $i, T_{i}$ represents the fixed effect of CBY treatments (i: CON, CBY-I, CBY-II, and CBY-III), $P_{j}$ represents the fixed periods (j: initial and final), $(T \times P)_{i j}$ represents the fixed effect of interaction between the treatment and period, and $e_{i j k}$ represents the random error.

\section{Results and discussion}

In recent years, like in other developing countries there has been a growing demand among consumers for leaner meats, especially in the western part of Turkey, due to high population and socio-economic

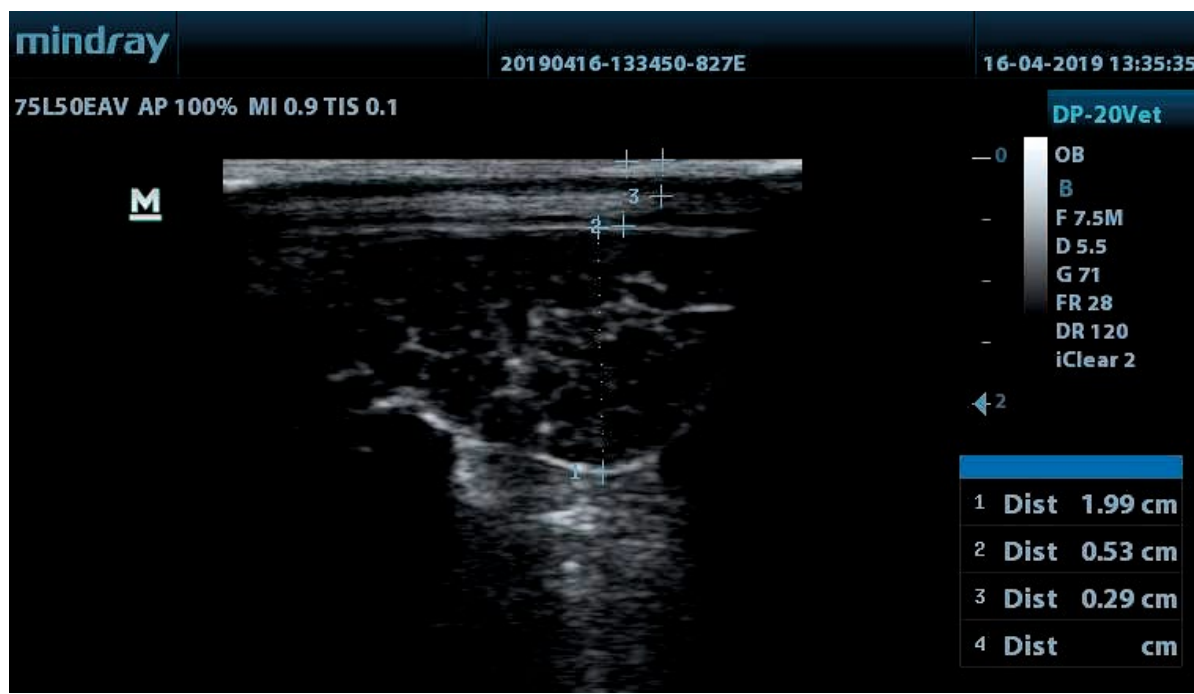

Fig. 1. A sample image from ultrasound measurement

Explanations: 1 - MLD depth; 2 - FT + skin; 3 - skin

Tab. 2. Effect of CBY on MLD and FT of Kivircik lambs

\begin{tabular}{|l|c|c|c|c|c|c|c|c|c|c|c|}
\hline \multirow{2}{*}{ Variable } & \multicolumn{4}{|c|}{ Treatments } & \multirow{2}{*}{ SEM } & \multicolumn{2}{c|}{ Periods } & \multirow{2}{*}{ SEM } & \multicolumn{3}{|c|}{ Effects } \\
& CON & CBY-I & CBY-II & CBY-III & & I & F & & T & P & T $\times$ P \\
\hline MLD, cm & 2.14 & 2.14 & 2.18 & 2.24 & 0.05 & $2.06^{\mathrm{b}}$ & $2.29^{\mathrm{a}}$ & 0.03 & 0.399 & 0.000 & 0.166 \\
FT, mm & 2.59 & 2.72 & 2.81 & 2.40 & 0.16 & 2.58 & 2.68 & 0.11 & 0.279 & 0.560 & 0.010 \\
I & 2.80 & 2.28 & 3.01 & 2.24 & & & & & & & \\
F & 2.38 & 3.16 & 2.61 & 2.55 & & & & & & & \\
\hline
\end{tabular}

Explanations: $\mathrm{a}, \mathrm{b}-$ values within a row with different superscripts differ significantly at $\mathrm{p}<0.05$; MLD - musculus longissimus dorsi; FT - fat thickness; SEM - standard error of mean; I - initial; F - final; T treatment; $\mathrm{P}$ - period; $\mathrm{T} \times \mathrm{P}$ - interaction between treatment and period factors. The competition between producers, mostly out of lambing season, results in higher fat ratio on eye muscle and causes economic losses. Therefore, it has been well understood that the natural feed additives are important in increasing MLD and reducing FT. The effect of CBY on MLD and FT in Kivircik lambs and a sample image from the ultrasound measurement were given in the Table 2 and Figure 1, respectively. The results showed that there was no significant difference between the treatments in terms of MLD and FT ( $>>0.05)$. On the other hand, the effect of the period on MLD $(p<0.001)$ and the effect of interaction between the treatments and periods on FT $(p<0.01)$ were found to be significant. These results obtained from the ultrasound measurements suggested that it was possible to yield the carcasses with higher MLD $(+1.87 \%$ in CBY-II and $+4.67 \%$ in CBY-III $)$ and lower FT (-13.29\% in CBY-II).

The basic statistics for LW, ultrasound and body measurements used in calculating body indexes are given in the Table 3 . The overall coefficients of variation of body measurements were $6.90 \%$ and $6.86 \%$ at the initial and final stage of fattening, respectively (except LW which was over $10 \%$ in both stages), which meant there was a homogeneity in this breed. In contrast to the body measurements, there was a greater variance between the animals in terms of FT (30.20-31.29) and MLD (10.46-11.22) compared to other variables.

There was no significant $(\mathrm{p}>0.05)$ interaction between the treatments and periods in both ethnological and functional indices (Tab. 4); thus, only the main effects were presented. It was understood from Table 4 that there were no significant $(\mathrm{p}>0.05)$ differences between the treatments in all investigated indexes, except IH. This may be explained by the differences in terms of muscularity and adiposity in the treatments groups. The ultrasound measurements were found to be in accordance with these results.

$\mathrm{IBF}$, one of the three somatic indexes along with $\mathrm{IC}$ and $\mathrm{IH}$, gives an idea about the breed body frame. In this study, the lambs in all treatments had a rectangular body frame, except CON (> 103). The least IBF value was observed in CON as 102.01 with a square body frame $(>97$ and $<103$ ). 
Tab. 3. Basic statistics on LW, ultrasound and body measurements involved in the study

\begin{tabular}{|c|c|c|c|c|c|c|}
\hline Variable & Period & Mean \pm SEM & Variance & CV & Min & Max \\
\hline \multirow{2}{*}{ LW, kg } & I & $23.80 \pm 0.46$ & 10.19 & 13.42 & 17.38 & 29.78 \\
\hline & $F$ & $36.71 \pm 0.69$ & 22.88 & 13.03 & 23.70 & 44.75 \\
\hline \multirow{2}{*}{ MLD, cm } & I & $2.06 \pm 0.03$ & 0.05 & 11.22 & 1.56 & 2.65 \\
\hline & $F$ & $2.29 \pm 0.03$ & 0.06 & 10.46 & 1.91 & 2.91 \\
\hline \multirow{2}{*}{$\mathrm{FT}, \mathrm{mm}$} & I & $2.58 \pm 0.12$ & 0.07 & 31.29 & 1.10 & 6.30 \\
\hline & $F$ & $2.67 \pm 0.12$ & 0.07 & 30.20 & 1.40 & 4.50 \\
\hline \multirow{2}{*}{ BL } & I & $59.25 \pm 0.39$ & 7.43 & 4.60 & 53 & 64 \\
\hline & $F$ & $66.11 \pm 0.37$ & 6.70 & 3.91 & 56 & 69.5 \\
\hline \multirow{2}{*}{ WH } & I & $57.59 \pm 0.43$ & 9.21 & 5.27 & 52 & 63.5 \\
\hline & $\mathbf{F}$ & $63.79 \pm 0.35$ & 5.88 & 3.80 & 60 & 69.5 \\
\hline \multirow{2}{*}{ RH } & I & $57.91 \pm 0.40$ & 7.77 & 4.81 & 52.5 & 63 \\
\hline & $\mathrm{F}$ & $65.02 \pm 0.39$ & 7.51 & 4.21 & 60.5 & 71.5 \\
\hline \multirow{2}{*}{ RW } & I & $11.40 \pm 0.15$ & 1.07 & 9.09 & 9.5 & 15 \\
\hline & $F$ & $12.88 \pm 0.17$ & 1.47 & 9.41 & 11 & 17 \\
\hline \multirow{2}{*}{ CD } & I & $19.58 \pm 0.21$ & 2.07 & 7.34 & 16.5 & 22 \\
\hline & $F$ & $22.57 \pm 0.25$ & 3.09 & 7.79 & 19 & 26 \\
\hline \multirow{2}{*}{ CW } & I & $13.15 \pm 0.16$ & 1.22 & 8.41 & 10.5 & 15 \\
\hline & $\mathrm{F}$ & $16.33 \pm 0.21$ & 2.12 & 8.91 & 12.5 & 19.5 \\
\hline \multirow{2}{*}{ CC } & I & $64.45 \pm 0.49$ & 11.52 & 5.27 & 57 & 73 \\
\hline & $\mathrm{F}$ & $75.85 \pm 0.62$ & 18.48 & 5.67 & 65 & 83.5 \\
\hline \multirow{2}{*}{ CBP } & I & $7.29 \pm 0.04$ & 0.08 & 3.91 & 6.7 & 7.9 \\
\hline & $\mathrm{F}$ & $7.69 \pm 0.06$ & 0.15 & 5.00 & 7 & 8.5 \\
\hline
\end{tabular}

Explanations: LW - live weight; MLD - musculus longissimus dorsi; FT - fat thickness; BL - body length; WH - withers height; RH - rump height; RW rump width; $\mathrm{CD}$ - chest depth; $\mathrm{CW}$ - chest width; $\mathrm{CC}$ - chest circumference; $\mathrm{CBP}$ - cannon bone perimeter; SEM - standard error of mean; CV - coefficient of variance; I - initial; F - final

IA, known as index of conformation, ratio between squared $\mathrm{CC}$ and $\mathrm{WH}$, gives useful information about meat production capability and is mostly used in the selection program in animal breeding. In their study on Cornigliese sheep breed, Sabbioni et al. (18) found that the age-class, year of birth and flock $(\mathrm{p}<0.001)$ and lambing type $(\mathrm{p}<0.05)$ significantly affected the IA whereas the sex did not $(\mathrm{p}>0.05)$. The same researchers found the index of compactness in Cornigliese sheep breed as 84.24 in the males at the age of $0-6$ months. Another study clearly showed that the breed type significantly affected IA (13). Considering the differences in terms of the fattening parameters versus characterization of breeds, the results of our study were in accordance with those of the studies in the literature.

The animals with relative ITD values above 120 have a good thorax development (13). In the present study, CBY-II yielded the highest ITD value which was $1.85 \%$ higher than that of CON. In their study on six different sheep breeds (two Slovenian and four Montenegrin), Marković et al. (13) reported higher values than the values obtained in our study. However, it may be possible to increase these values by extending the fattening period, which has a significant effect on ITD.

DTI indicates thoracic development and gives valuable information about the current status of the animal. In our study, all the lambs in all treatments, except CBY-III, could be classified as light lambs $(>10.50$ and $<10.80)$. The highest DTI value was observed in CBY-III as 10.90 and the lambs in this group could be classified as intermediary lambs. These results were higher than those obtained by Esquivelzeta et al. (8) in their study on the Ripollesa sheep breed and Hernández et

Tab. 4. Effect of CBY on ethnological and functional indices of Kivircik lambs

\begin{tabular}{|c|c|c|c|c|c|c|c|c|c|c|c|}
\hline \multirow{2}{*}{ Index } & \multicolumn{4}{|c|}{ Treatments } & \multirow{2}{*}{ SEM } & \multicolumn{2}{|c|}{ Periods } & \multirow{2}{*}{ SEM } & \multicolumn{3}{|c|}{ Effects } \\
\hline & CON & CBY-I & CBY-II & CBY-II & & I & $\mathbf{F}$ & & $T$ & $\mathbf{P}$ & $T \times P$ \\
\hline IBF & 102.01 & 104.40 & 103.14 & 103.94 & 0.90 & 103.01 & 103.74 & 0.63 & 0.254 & 0.418 & 0.617 \\
\hline IC & 71.17 & 67.73 & 71.92 & 69.02 & 1.30 & $67.34^{b}$ & $72.58^{\mathrm{a}}$ & 0.92 & 0.092 & 0.000 & 0.588 \\
\hline IH & 99.25 & 97.64 & 99.41 & 98.92 & 0.49 & $99.48^{a}$ & $98.13^{b}$ & 0.34 & 0.048 & 0.007 & 0.767 \\
\hline ICD & 34.04 & 35.62 & 34.30 & 34.87 & 0.33 & $34.04^{b}$ & $35.38^{\mathrm{a}}$ & 0.33 & 0.088 & 0.005 & 0.828 \\
\hline ITD & 114.30 & 116.22 & 116.41 & 114.88 & 1.00 & $111.98^{b}$ & $118.92^{\mathrm{a}}$ & 0.71 & 0.372 & 0.000 & 0.820 \\
\hline DTI & 10.68 & 10.78 & 10.61 & 10.90 & 0.10 & $11.33^{a}$ & $10.16^{b}$ & 0.08 & 0.202 & 0.000 & 0.309 \\
\hline IA & 79.73 & 82.01 & 82.55 & 80.89 & 1.47 & $72.23^{b}$ & $90.37^{a}$ & 1.04 & 0.538 & 0.000 & 0.388 \\
\hline IRCB & 12.18 & 12.50 & 12.32 & 12.49 & 0.11 & $12.68^{a}$ & $12.06^{b}$ & 0.08 & 0.136 & 0.000 & 0.683 \\
\hline IBW & 48.62 & 49.63 & 49.78 & 49.31 & 1.13 & $41.21^{b}$ & $57.46^{a}$ & 0.80 & 0.891 & 0.000 & 0.922 \\
\hline
\end{tabular}

Explanations: $\mathrm{a}, \mathrm{b}-$ values within a row with different superscripts differ significantly at $\mathrm{p}<0.05$; IBF - index of body frame; IC index of chest; IH - index of height; ICD - index of chest depth; ITD - index of thorax development; DTI - dactyl thorax index; IA - index of anamorphosis; IRCB - index of relative cannon bone; IBW - index of body weight; I - initial; F - final; SEM - standard error of mean; $\mathrm{T}$ - treatment; $\mathrm{P}$ - period; $\mathrm{T} \times \mathrm{P}$ - interaction between treatment and period 
al. (10) in their study on the Merino Socorro Island sheep breed.

It was concluded that adding CBY to the lamb diets could be used to increase the MLD depth without increasing the FT in the fattening period. Moreover, these results indicated that using CBY in fattening lamb diet with a dose of $3 \mathrm{~g} / \mathrm{kg}$ (as fed basis) had beneficial effects on the body indexes. Nevertheless, it is highly recommended that further studies be carried out on CBY to examine its effect on carcass quality.

\section{References}

1. AOAC.: Official Methods of Analysis. ( $15^{\text {th }}$ ed.). vol. 1, Association of Official Analytical Chemists, Arlington, VA, USA 1990.

2. Blair R.: Nutrition and feeding of organic pigs. CABI, Wallingford, Oxon, UK 2017, p. 143.

3. Callaway E. S., Martin S. A.: Effects of a Saccharomyces cerevisiae culture on ruminal bacteria that utilize lactate and digest cellulose. J. Dairy Sci. 1997, 80, 2035-2044.

4. Chacon E., Macedo F., Valezquez F., Pavia S. R., Pienda E., McManus C.: Morphological measurements and body indices for Cuban Creole goats and their crossbred. R. Bras. Zootec. 2011, 40, 1671-1679.

5.Demir E., Eseceli H., Özcan A. M.: Effect of activated clinoptilolite in aflatoxin B1 contaminated laying hen diets on aflatoxin B1 residues and quality of eggs. Zb. Matice srp. prir. Nauke. 2017, 133, 13-22.

6. Dobicki A., Preś J., Łuczak W., Szyrner A.: Influence of dried blewery's yeast on body weight gains, physiological and bioehemical indicators of blood and deuelopment of the lumen micto-olganisms in calves. Med. Weter. 2005, 61, 946-949.

7. Esen S., Karadağ H., Kaptan C., Oğuz E., Günşen U., Eseceli H.: Aktive Edilmiş Klinoptilolit ve İnaktif Bira Mayası İçeren Karışımın Bandırma'da Yetiştirilen Kıvırcık Irkı Kuzu Rasyonlarına İlavesinin Besi Performansı Üzerine Etkisi. $2^{\text {nd }}$ International Symposium of Bandirma and its Surroundings - UBS'19, Bandirma, Turkey 2019, p. 69-75.

8. Esquivelzeta C., Fina M., Bach R., Madruga C., Caja G., Casellas J., Piedrafita J.: Morphological analysis and subpopulation characterization of Ripollesa sheep breed. Animal Genetic Resources 2011, 49, 9-17, doi: 10.1017/ S2078633611000063.
9. Hcini E., Slima A. B., Kallel I., Zormati S., Traore A. I., Gdoura R.: Does supplemental zeolite (clinoptilolite) affect growth performance, meat texture, oxidative stress and production of polyunsaturated fatty acid of Turkey poults? Lipids Health Dis. 2018, 17, 177, doi: 10.1186/s12944-018-0820-7.

10. Hernández J. A., Lepe M., Macedo R., Arredondo V., Cortez C. E., García L. J., Prado O.: Morphological study of Socorro Island Merino sheep and its crosses with hair breeds. Trop. Anim. Health Pro. 2017, 49, 173-178.

11. Khargharia G., Kadirvel G., Kumar S., Doley S., Bharti P. K., Mukut D.: Principal component analysis of morphological traits of Assam hill goat in eastern Himalayan India. J. Anim. Plant Sci. 2015, 25, 1251-1258.

12. Kumar U., Sareen V. K., Singh S.: Effect of yeast culture supplement on ruminal microbial populations and metabolism in buffalo calves fed a high roughage diet. J. Sci. Food Agric. 1997, 73, 231-236.

13. Marković B., Dovč P., Marković M., Radonjić D., Adakalić M., Simčič M.: Differentiation of some Pramenka sheep breeds based on morphometric characteristics. Arch. Anim. Breed. 2019, 62, 393-402, doi: 10.5194/ aab-62-393-2019.

14. Milewski S.: Effect of yeast preparations Saccharomyces cerevisiae on meat performance traits and blood hematological indices in sucking lambs. Med. Weter. 2009, 65, 51-54.

15. Minitab.: Minitab I: Statistical software for Windows, Release 17. Minitab Inc., USA, 2014

16. Papaioannou D., Katsoulos P. D., Panousis N., Karatzias H.: The role of natural and synthetic zeolites as feed additives on the prevention and/or the treatment of certain farm animal diseases: A review. Micropor. Mesopor. Mat. 2005, 84, 161-170.

17. Parés-Casanova P. M.: Morphometric dimensions allow differentiation of lamb carcasses for some breeds. Egypt. J. Sheep Goat Sci. 2013, 8, 167-170.

18. Sabbioni A., Beretti V., Righi F., Superchi P.: Allometric coefficients for body measures and morphometric indexes in a meat-type sheep breed. Small Ruminant Res. 2016, 144, 248-254.

19. Salako A. E.: Application of morphological indices in the assessment of type and function in sheep. Int. J. Morphol. 2006, 24, 13-18.

20. Souza R. C. L. de, Rech J. L., Fischer V., Wiegand M. M., Moreira H. L. M., Osório M. T. M., Siewerdt F.: Body development, carcass, and meat quality of confined lambs fed increasing levels of whole rice meal. Trop. Anim. Health Pro. 2014, 46, 191-195.

21. Yllmaz O., Cemal I., Karaca O.: Estimation of mature live weight using some body measurements in Karya sheep. Trop. Anim. Health Pro. 2013, 45, 397-403.

Corresponding author: MSc. Biol. \& Agric. Eng. Selim ESEN, Sheep Breeding Research Institute, 10200, Bandirma, Balikesir, Turkey; e-mail: selim_esen01@hotmail.com 